\title{
Análise de Não Conformidades em Edifícios Novos
}

\author{
V.S.A. Pasin ${ }^{1}$, A. Lorenzi ${ }^{2 *}$, L.S. Lorenzi ${ }^{2}$ \\ *Autor de Contacto: alexandre.lorenzi@ufrgs.br \\ ${ }^{1}$ Departamento de Engenharia Civil, Escola de Engenharia, Universidade Federal do Rio Grande do Sul, \\ Porto Alegre, Brasil \\ ${ }^{2}$ Departamento de Engenharia Civil, Escola de Engenharia, Instituto de Desempenho da UFRGS, Universidade \\ Federal do Rio Grande do Sul, Porto Alegre, Brasil
}

\begin{abstract}
RESUMO
A construção civil, comparada às outras indústrias, apresenta um elevado índice de não conformidades, que podem acarretar na redução da vida útil, do valor da edificação e da satisfação dos clientes. A garantia, na indústria da construção civil, é um item questionado quanto a sua aplicabilidade, por tratar de bens duráveis com longa vida útil e que, devido a um enorme número de variáveis que o compõem, são produtos únicos. As construtoras possuem um setor específico de Assistência Técnica para atendimento das obras prontas, ou seja, no período pós-venda que analisa a não conformidade no local. $\mathrm{O}$ objetivo deste trabalho é um estudo de caso de levantamento e categorização das não conformidades o posterior estudo das possíveis causas.
\end{abstract}

Palabras clave: Assistência Técnica; Custos; Manifestações Patológicas.

Citar como: V.S.A. Pasin, A. Lorenzi, L.S. Lorenzi (2021), “Análise de não conformidades em edifícios novos", CONPAT 2021, XVI, pp. xxx-xxx, DOI: http://dx.doi.org/xxxxxxxxxx

\section{RESUMEN}

La construcción civil, en comparación con otras industrias, tiene un alto índice de no conformidades. Este hecho puede conducir a una reducción de la vida útil, el valor de la edificación 
y la satisfacción del cliente. La garantía, en la industria de la construcción civil, es un rubro cuestionado en cuanto a su aplicabilidad, ya que se trata de bienes duraderos con una larga vida útil y que, debido a la gran cantidad de variables que la integran, son productos únicos. Las empresas constructoras cuentan con un sector de Asistencia Técnica específico para atender las obras terminadas, es decir, en el período de postventa, que analiza los incumplimientos en el sitio. El objetivo de este trabajo es un estudio de caso de relevamiento y categorización de no conformidades y el posterior estudio de las posibles.

Palabras clave: Asistencia técnica; Costos; Manifestaciones patológicas.

\begin{abstract}
Civil construction, compared to other industries, has a high rate of non-conformities. This fact can lead to a reduction in the useful life, building value and customer satisfaction. Warranty, in the civil construction industry, is questioned as to its applicability, as it deals with durable goods with a long useful life and which, due to a huge number of variables that make up, are unique products. The construction companies have a specific Technical Assistance Sector to attend to the finished works, that is, in the post-sale period, which analyzes non-compliance at the site. The objective of this work is a case study of survey and categorization of non-conformities for further study of possible ones.
\end{abstract}

Keywords: Technical Assistance; Costs; Pathological Manifestations.

\title{
1. INTRODUÇÃO
}

A ANBT NBR 15575 (ABNT, 2013), ao estabelecer critérios e parâmetros para que os requisitos dos usuários sejam atendidos, constituiu uma grande inovação tecnológica para o setor da construção civil, auxiliando na organização do processo construtivo imobiliário, por meio da definição de competências e funções para projetistas, incorporadores, fornecedores de produto e usuários, contribuindo com a ordenação do mercado de consumo no âmbito da construção civil e também cooperando com o meio jurídico, (MOREIRA, 2019).

A visão sistêmica compreende os edifícios como complexos (sistemas) funcionais maiores, constituídos de vários subsistemas componíveis de formas diversas, ou seja, pode ser utilizado como critério de classificação das não conformidades. As falhas construtivas podem surgir pelos seguintes fatores: a) inobservância a normas técnicas; b) inobservância à legislação; c) falhas intrínsecas, de qualidade do trabalho, decorrentes de dimensionamento ou especificações inadequadas ou equivocadas; d) incompatibilidade de materiais; e) má utilização ou manutenção inadequada, (DEL MAR, 2015)

A garantia, na indústria da construção civil, é um item questionado quanto a sua aplicabilidade, por tratar de bens duráveis com longa vida útil e que, devido a um enorme número de variáveis que o compõem, são produtos únicos. A garantia consiste num mecanismo de defesa do usuário das edificações e é baseada no Código Civil e Código de Defesa do Consumidor, estando presente também na Norma de Desempenho (NBR 15575:2013). Destaca-se que o assunto é tão importante que a Associação Brasileira de Normas Técnicas criou a Comissão de Estudo de Garantias das Edificações, no dia 26 de fevereiro de 2021, e tem como âmbito de atuação a normalização no campo de garantias das edificações, compreendendo a aplicação das condições de garantias a serem 
atendidas nas fases de concepção, construção, entrega, uso, operação e manutenção das edificações, no que concerne à requisitos, diretrizes, procedimentos e generalidades, (CBIC, 2021).

No Brasil, com exceção de alguns levantamentos preliminares efetuados pelo IPT (Instituto de Pesquisas Tecnológicas de São Paulo) em conjuntos habitacionais construídos no interior, não se tem notícia da compilação de dados sobre as origens dos problemas patológicos nos edifícios e sobre as suas formas mais típicas de manifestação. Apesar de tratar de manifestações patológicas, pode-se estender esta colocação para as não conformidades em geral, Thomaz apud Del Mar (2015). Hoje, as construtoras possuem um setor específico de Assistência Técnica para atendimento das obras prontas, ou seja, no período pós-venda. Após um usuário informar à construtora que há uma não conformidade, é designado um técnico para verificação da não conformidade no local. Deste modo, cabe ao responsável o diagnóstico da causa da não conformidade, se está abrangida pela garantia, se está ou não dentro do prazo para aplicação da garantia e definição da solução a ser adotada.

O objeto deste trabalho é um estudo de caso de levantamento e categorização das não conformidades o posterior estudo das possíveis causas. O trabalho possui foco nos dados de assistência técnica da empresa que construí os edifícios em estudo e será utlizada documentação disponibilizada pela empresa. O presente trabalho tem como objetivo principal levantar e categorizar as não conformidades em edifícios novos visando verificar quais sistemas ou subsistemas apresentam o maior número de ocorrências de não conformidades e analisar quais são suas principais causas. O levantamento e análise dos dados fornecerão informações que acarretam aperfeiçoamento de processos, melhoria de projetos e redução de custos em futuras construções.

\section{REFERENCIAL TEÓRICO}

Projetar é também levar em conta alguns outros aspectos tais como: custo de manutenção e durabilidade. Ambos diretamente relacionados com o maior ou menor conhecimento que o projetista tem das propriedades tecnológicas dos materiais de construção a serem empregados (THOMAZ, 2001). A qualidade na construção civil principalmente em obras residenciais está apoiada em alguns fundamentos como desempenho, confiabilidade, conformidade, durabilidade e assistência técnica do produto final. Quando se consegue que estes elementos se inter-relacionem, com certeza se garantirá um produto conforme (a unidade residencial) e o cliente satisfeito. Para que isto aconteça é necessário um estudo aprofundado sobre as não-conformidades, como elas ocorrem, como evitar seu surgimento, pois essas patologias envolvem custos diretos e indiretos nem sempre previstos, onerando a empresa. O importante é não deixar que os desvios aconteçam, e se acontecerem, serem identificados e corrigidos o mais breve possível, (ADAMI, 2008).

O desempenho de uma edificação e dos sistemas construtivos que a compõem consiste no comportamento que apresentam diante das condições de uso a que estarão sujeitos ao longo de toda a vida útil e das condições de exposição, como as climáticas da região, sendo chuva, umidade, temperaturas e variação térmica, ventos, descargas atmosféricas e outras, a saber, como vibrações causadas pela proximidade de uma via férrea, exposição aos ruídos do tráfego normal nas vias, (COVELO SILVA e FROLINI, 2019).

A gestão da qualidade consiste no conjunto de atividades coordenadas para dirigir e controlar uma organização em relação à qualidade dos serviços prestados ou dos seus produtos, englobando o planejamento, o controle, a garantia e a melhoria da qualidade. Esses quatro conceitos não são partes de uma empresa, mas pertencem à função qualidade. A melhoria da qualidade ocorre também nas outras três atividades, portanto, há a melhoria da qualidade no planejamento, controle e garantia (MIGUEL, 2005). A figura 1 demonstra a inter-relação entre o conceito de qualidade, gestão da qualidade e os elementos que a compõem. 


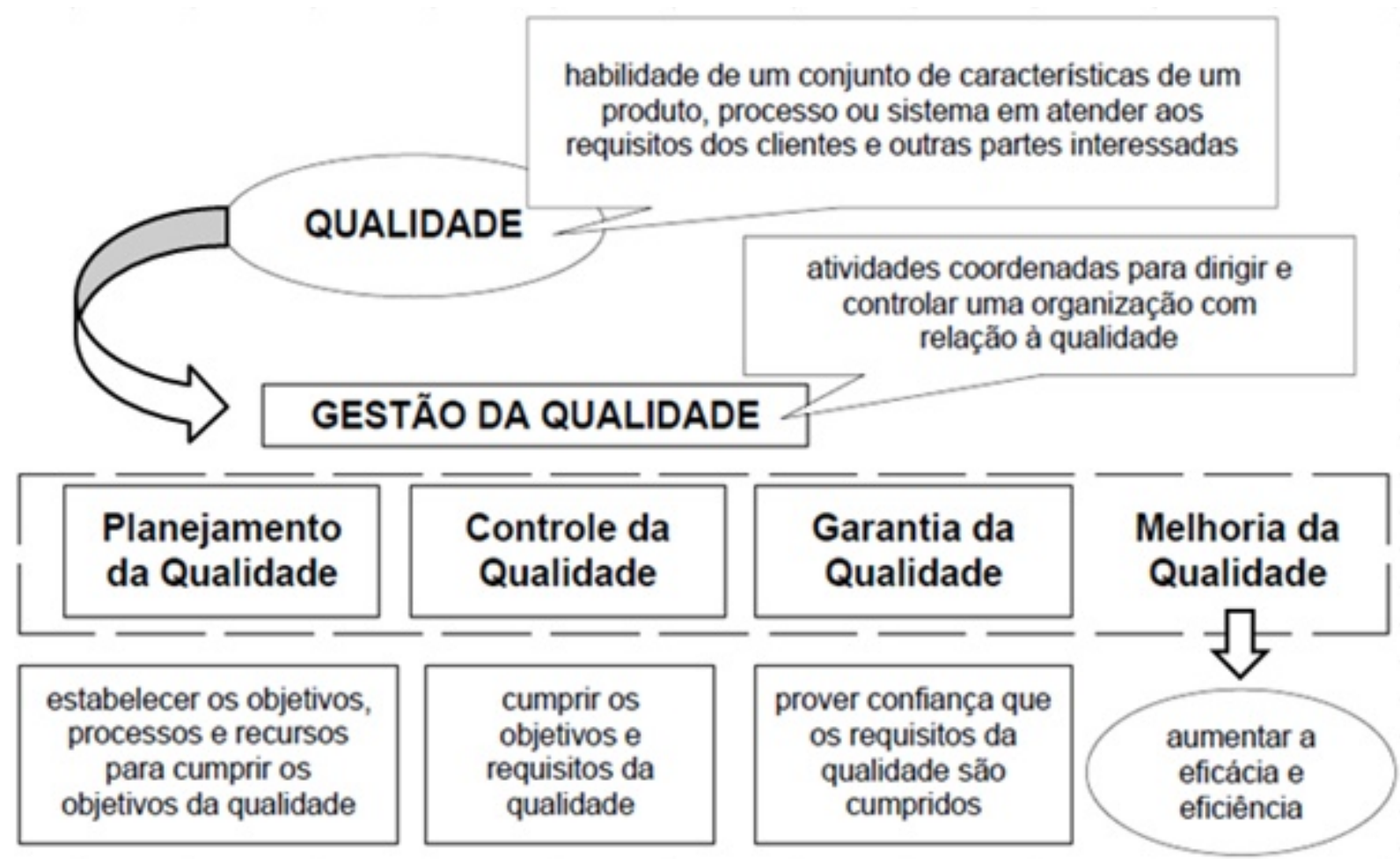

Figura 1: Inter-relação entre o conceito de qualidade, Gestão da Qualidade e elementos que a compõem, Miguel (2005)

O Gerenciamento da Qualidade Total atinge todas as áreas funcionais de uma organização em cada nível operacional, visando à melhoria continua da produtividade em cada nível de operação. As melhorias são voltadas para satisfazer custo, qualidade, visão de mercado, planejamento e crescimento da empresa, combinando técnicas fundamentais de administração, inovação e técnicas especiais para melhoria contínua de processos. Por sua vez, devem-se utilizar todos os recursos financeiros e humanos disponíveis, demandando comprometimento, disciplina e um esforço crescente (BROCKA, BROCKA, 1994).

Segundo Del Mar (2015), a garantia contratual é complementar à garantia legal, ampliando e concedendo maiores condições de garantia ao produto ou serviço, não apenas no prazo, mas podendo ser acondicionadas a determinadas hipóteses, sendo total ou parcial. Essa garantia não pode excluir ou diminuir nada que é obrigatório e assegurado pela lei. É concedida ao consumidor pelo fornecedor quando há vontade entre as partes, possuindo caráter voluntário, deixando ao critério do fornecedor ou àquilo que se estabelecer em cláusula ou contrato específico.

Os custos gerados pela ausência da qualidade é também gerencial, pois um sistema eficientedeveplanejar, controlar, possui indicadores e verifica a eficácia de todos os procedimentos e setores envolvidos. A qualidade na construção civil principalmente em obras residenciais está apoiada em alguns fundamentos como desempenho, confiabilidade, conformidade, durabilidade e assistência técnica do produto final. Quando se consegue que estes elementos se interrelacionem, com certeza se garantiráum produto conforme (a unidade residencial) e o cliente satisfeito.Para que isto aconteça é necessário um estudo aprofundado sobre as nãoconformidades, como elas ocorrem, como evitar seu surgimento, pois essas patologias envolvem custos diretos e indiretos nem sempre previstos, onerando a empresa. O importante é não deixar que os desvios aconteçam, e se acontecerem, serem identificados e corrigidos o mais breve possível, (ADAMI, 2008). 
A ABNT NBR 15575-1:2013 fornece a orientação para serem estabelecidos os prazos mínimos de garantia para as edificações para o qual elementos, componentes e sistemas atendam condições de funcionalidade.

\section{METODOLOGIA}

Todas as não conformidades presentes na construção civil tem uma origem. O processo de atendimento para serviços de assistência técnica inicia-se com a solicitação do proprietário, no caso de unidades privativas, ou do síndico, no caso de áreas condominiais. Esta é considerada a data de início da não conformidade, pois é o momento no qual fica registrado para o construtor.

Por sua vez, após a abertura da solicitação, é realizada uma análise inicial, onde é verificado que se trata de uma não conformidade ou não, classificando em vício ou defeito construtivo e, $\operatorname{logo}$ a seguir, é agendada a vistoria. Durante a atividade de vistoria, visita-se o local e faz-se uma verificação da não conformidade, determinando em qual sistema construtivo está ocorrendo e as quais elementos ou componentes pertencem. Assim, pode-se determinar se é de responsabilidade da construtora, ou trata-se de responsabilidade do proprietário, seja por esgotamento do prazo de garantia ou culpa exclusiva do usuário. Se for responsabilidade da construtora, procede-se com o reparo, caso contrário, informa-se o proprietário ou síndico e encerra-se a solicitação.

$\mathrm{Na}$ atividade de reparo, deve-se definir o procedimento de correção que será empregado. Programase a realização do serviço, procedendo com a compra de materiais e alocando a mão de obra para execução.

Quando o reparo está finalizado, é realizada a entrega para a pessoa que fez a solicitação. Se o serviço é aprovado, o proprietário ou síndico assina o recebimento do reparo e a solicitação é encerrada e arquivada pela empresa. Se o serviço não for aprovado, tomam-se ações corretivas de modo a que se aceite os serviços e seja assinado o termo de aceitação.

\section{LEVANTAMENTO DE DADOS}

O presente trabalho foi desenvolvido com base no levantamento das ocorrências geradas pelos usuários em dois empreendimentos localizados na cidade de Porto Alegre, após a sua entrega pela construtora. Este etapa destina-se à apresentação desse levantamento e sua análise com o objetivo de encontrar quais são as não conformidades mais relevantes a fim de estudar suas possíveis causas.

\subsection{Ocorrências Totais}

Coletaram-se os dados no registro presente no sistema do setor de Assistência Técnica da construtora para os dois empreendimentos em estudo para o período de 1 (um) ano. Ao todo, foram analisadas 471 (quatrocentas e setenta e uma) ocorrências entre $1^{\circ}$ de Agosto de 2017 e 31 de Julho de 2018. Primeiramente, calculou-se a média de ocorrências em relação à área de cada empreendimento. Este parâmetro forneceu um parâmetro comparativo preliminar entre os locais estudados, pois resulta uma grandeza qualitativa, não ficando somente com a grandeza quantitativa de ocorrências. A tabela 1 mostra a média citada acima para cada empreendimento.

Tabela 1. Ocorrências - média por área 


\begin{tabular}{|c|c|c|}
\hline & Empreendimento A & Empreendimento B \\
\hline Período & 1 ano & 1 ano \\
\hline Ocorrências & 352 & 119 \\
\hline $\begin{array}{c}\text { Área do empreendimento } \\
\left(\mathrm{m}^{2}\right)\end{array}$ & $17.898,31$ & $16.446,61$ \\
\hline Média $\left(\right.$ Ocorrências $\left./ 1000 \mathrm{~m}^{2}\right)$ & 19,67 & 7,24 \\
\hline
\end{tabular}

Verificou-se que, no empreendimento A, há uma taxa de 19,67 ocorrências por mil metros quadrados de área total. Já, no empreendimento B, a taxa é menor, sendo de 7,24 ocorrências por mil metros quadrados de área total. Embora os empreendimentos possuírem área total semelhante e serem estudados no mesmo período, há uma diferença relevante no número de ocorrências. Esta diferença, porém, não se pode atribuir pelos empreendimentos possuírem finalidades diferentes, pois, para chegar à conclusão que as diferentes finalidades dos empreendimentos influem no número de ocorrências, deve-se realizar uma análise com uma amostra maior de empreendimentos. Realizou-se a avaliação de cada ocorrência quanto a sua procedência. Isto acontece porque a empresa, por procedimento, registra todas as solicitações, deixando o sistema alimentado de informações sobre os empreendimentos e usuários. Utilizando a descrição do solicitante e o relato do técnico que há em cada ocorrência, foi realizada a divisão em dois grandes grupos: conforme e não conforme. As ocorrências não conformes são aquelas onde há uma não conformidade de fato. Ja as ocorrências conforme são separadas nos seguintes tipos:

a) Em conformidade: após verificação no local, não há problemas, considerando como improcedente a solicitação;

b) Solicitação de retorno: a ocorrência já está aberta, porém, por falta de comunicação, o solicitante pede informações sobre o andamento dos serviços;

c) Dúvida técnica: o solicitante pede informações sobre o imóvel, quanto a projetos, execução, garantias, entre outros.

Observa-se tambem que a proporção de ocorrências nas quais existem não conformidades em relação às totais é praticamente igual nos dois empreendimentos (Tabela 2).

Tabela 2. Proporção de ocorrências não conformes em relação às totais para cada empreendimento

\begin{tabular}{|c|c|c|}
\cline { 2 - 3 } \multicolumn{1}{c|}{} & Empreendimento A & Empreendimento B \\
\hline Ocorrências Totais & 352 & 119 \\
\hline Ocorrências Não Conformes & 265 & 91 \\
\hline Proporção (Não Conformes/Totais) & $75 \%$ & $76 \%$ \\
\hline
\end{tabular}

\subsection{Categorias da Ocorrências}

Após a separação dos grupos de ocorrências em conforme e não conformes, iniciou-se a análise das não conformidades. Separou-se cada item dentro de seis diferentes sistemas ou subsistemas construtivos, são eles:

a) Sistemas de Instalações;

b) Subsistemas de Esquadrias;

c) Subsistemas de Revestimentos; 
d) Subsistemas de Acabamentos;

e) Subsistemas de Paredes;

f) Subsistemas de Tratamentos.

A classificação em categorias foi feita levando-se em conta a solicitação e descrição do técnico, além de levar em conta a classificação colocada no sistema da construtora. Logo, montou-se um diagrama de Pareto para cada empreendimento a fim de verificar qual a relevância de cada categoria analisada (Figuras 2 e 3 ).

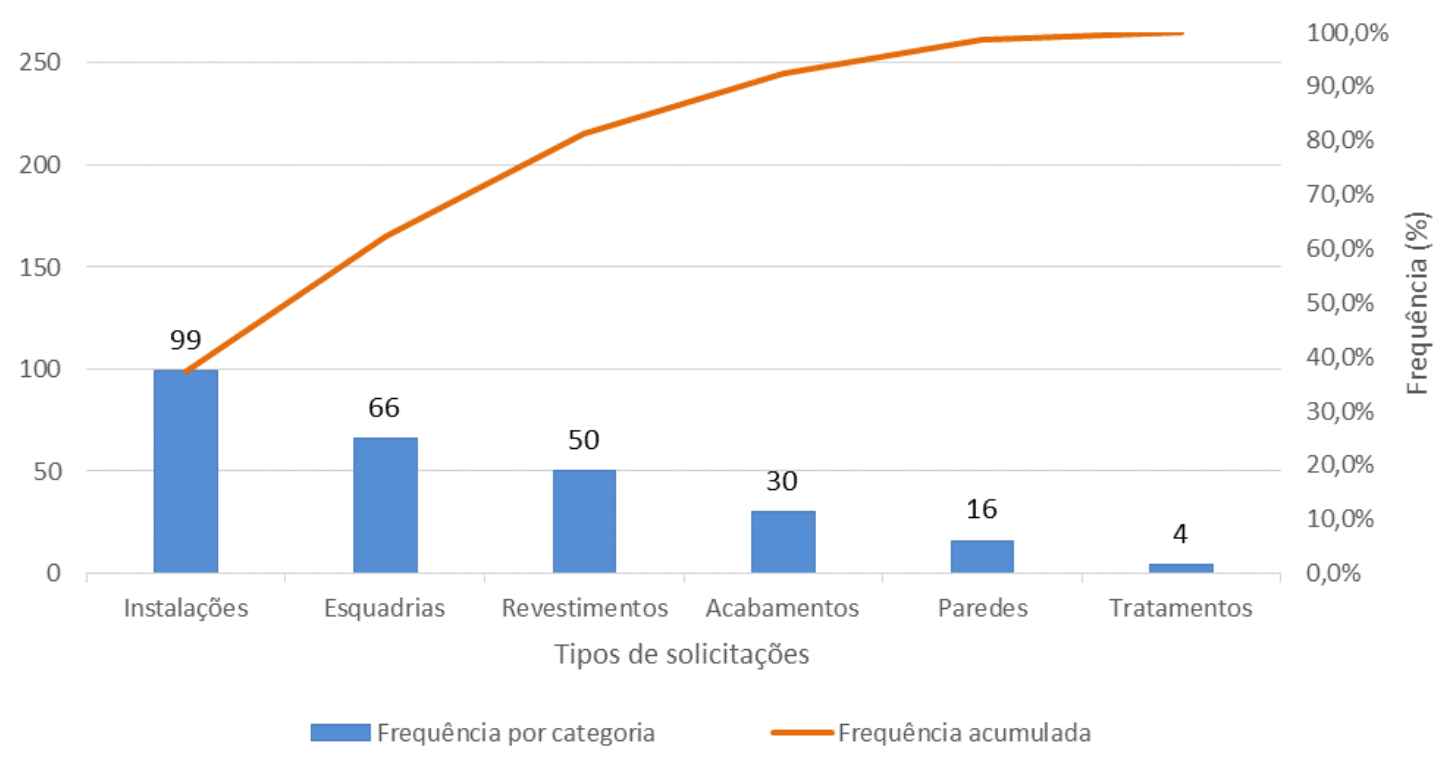

Figura 1: Frequência por categoria - Empreendimento A

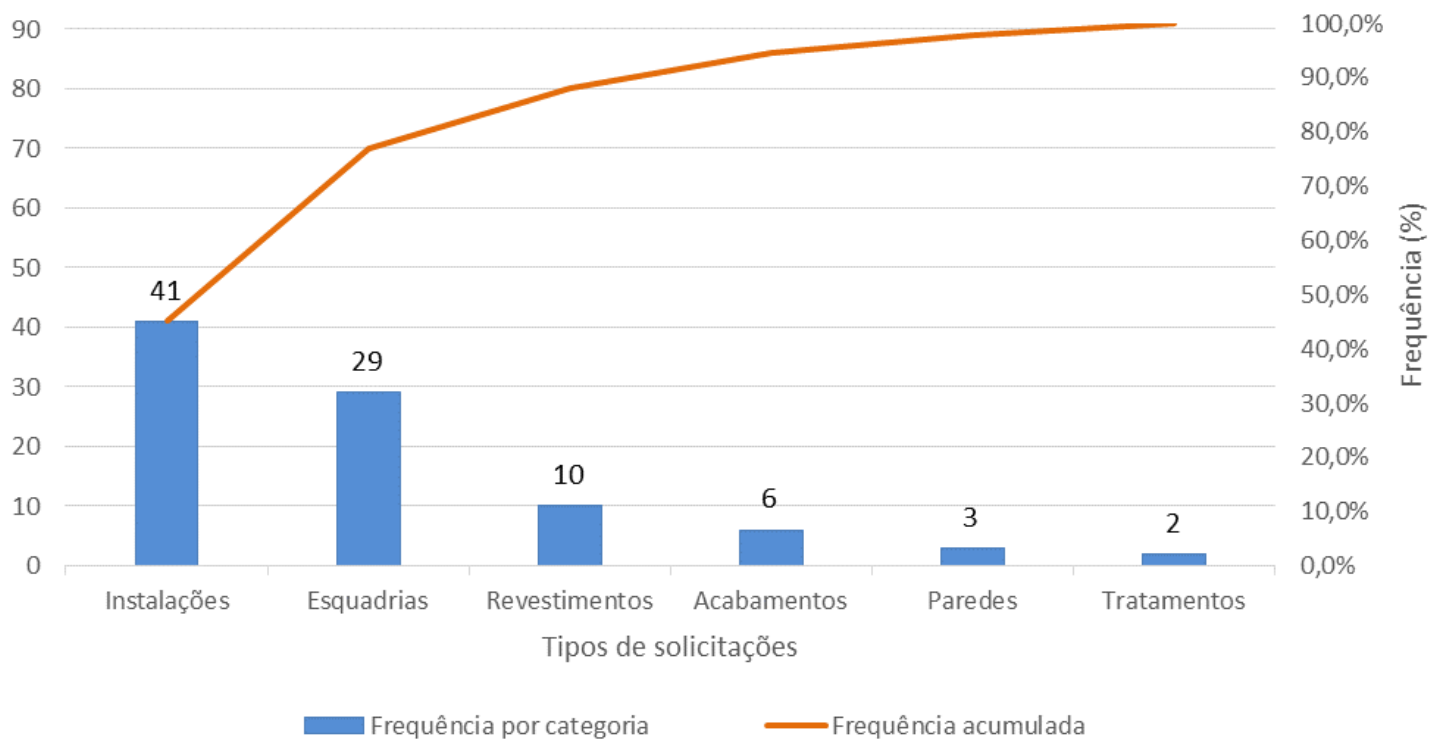

Figura 2: Frequência por categoria - Empreendimento B 
Ressalta-se que há um padrão na proporção de não conformidades para cada categoria quando se comparam os empreendimentos A e B. Pode-se observar que as três categorias com maior frequência concentram $81 \%$ das ocorrências não conformes no empreendimento $\mathrm{A}$ e $88 \%$ no empreendimento B. Deste modo, o estudo focou nestas três categorias para localizar quais são os tipos de não conformidades com maior repetição.

\section{ANÁLISE DAS NÃO CONFORMIDADES}

A inspeção predial baseia-se em analisar as anomalias e falhas identificadas nas edificações, levando em consideração o grau de risco oferecido aos usuários, ao meio ambiente e ao patrimônio. Podem-se relacionar fatores de manutenção, depreciação, saúde, segurança, funcionalidade, comprometimento de vida útil e perda de desempenho. A análise dos dados será realizada conforme recomendações que constam na Norma de Inspeção Predial (2012) do Instituto Brasileiro de Avaliações e Perícias de Engenharia (IBAPE).

O IBAPE (2012) define os graus de risco em três tipos:

a) Crítico: Risco de provocar danos contra a saúde e segurança das pessoas e do meio ambiente; perda excessiva de desempenho e funcionalidade causando possíveis paralisações; aumento excessivo de custo de manutenção e recuperação; comprometimento sensível de vida útil;

b) Médio: Risco de provocar a perda parcial de desempenho e funcionalidade da edificação sem prejuízo à operação direta de sistemas, e deterioração precoce;

c) Mínimo: Risco de causar pequenos prejuízos à estética ou atividade programável e planejada, sem incidência ou sem a probabilidade de ocorrência dos riscos críticos e regulares, além de baixo ou nenhum comprometimento do valor imobiliário.

\subsection{Empreendimento A}

As não conformidades selecionadas para serem analisadas foram as seguintes:

a) Vazamentos em instalações hidráulicas, sanitárias, pluviais;

b) Descascamentos de pintura em esquadrias de madeira;

c) Fissuras em revestimentos de argamassa. Coletaram

Os vazamentos são as não conformidades com maior frequência em Instalações hidráulicas, sanitárias, pluviais e de gás. Nota-se que são três locais com maior relevância: conexões de esgoto sanitário, caixa sifonada e conexão do vaso junto à tubulação. A Figura 3 exemplifica o dano secundário em um forro de gesso que havia em seu interior uma tubulação de esgoto sanitário com vazamento.

Quanto ao aspecto jurídico, trata-se de um vício oculto conforme o Código de Defesa do Consumidor, pois somente se manifesta durante a utilização do imóvel. O prazo recomendado pela NBR 15575:2013 é de três anos após o auto de conclusão do empreendimento, portanto, este tipo de não conformidade está em garantia pela construtora, salvo modificações que podem intervir no funcionamento destas instalações.

Como ponto de partida, foram relacionadas todas as possíveis causas para o vazamento nas instalações sanitárias e organizadas em um diagrama de causa-efeito. Foi considerado que a causa pode estar desde a fabricação até o momento no qual foi realizada a solicitação de abertura de ocorrência junto ao setor de assistência técnica da empresa, ou seja, inclui-se a parte de transporte, estocagem, instalação e utilização da instalação. A figura 4 ilustra o diagrama de causa-efeito gerado para este estudo. 


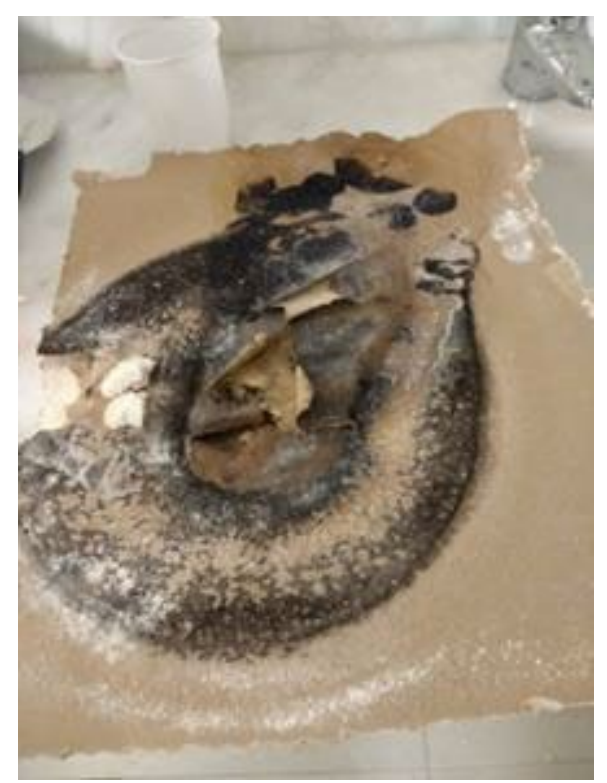

Figura 3: Danos secundários provocados por vazamento em instalações sanitárias

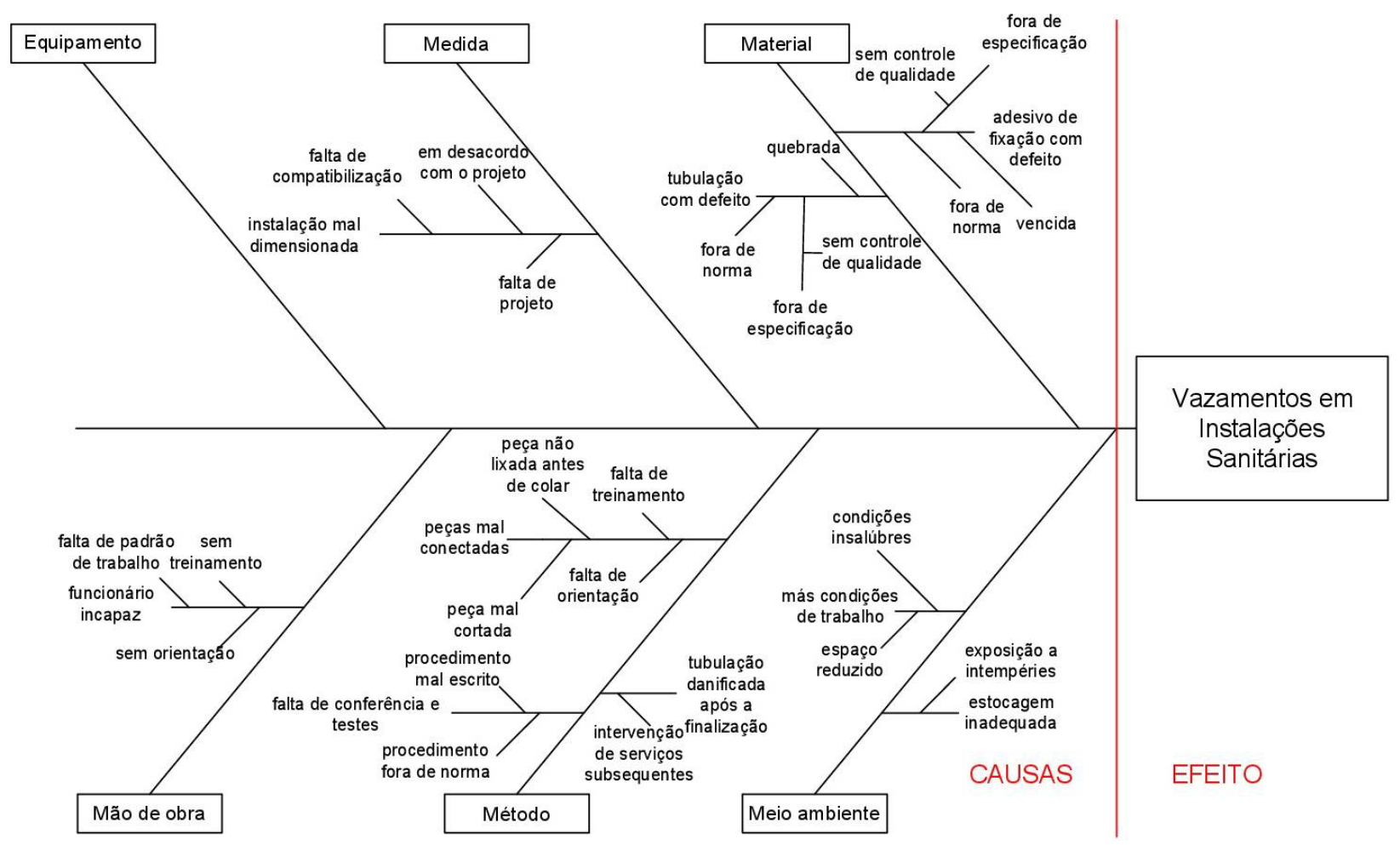

Figura 4: Diagrama de causa-efeito: vazamento em instalações sanitárias

Para a montagem da tubulação, é instruído que seja conforme a orientação do fabricante, o que deixa uma lacuna porque podem não ter sido treinados pelo fabricante, mas apenas pelo procedimento da construtora. O teste final deve ocorrer após a colocação dos metais e louças, simulando a utilização dos mesmos, incluindo o ponto de chuveiro, onde devem ser observados possíveis pontos de vazamentos. Esta última medida deveria extinguir a não conformidade em questão, logo pode estar não sendo aplicado em todos os locais, sendo que o serviço pode ter sido aceito sem realizar os testes solicitados em procedimento. 
Pode-se dizer é que há procedimentos quanto ao recebimento e estocagem do material, além de haver para a execução das instalações, que, se foram seguidos conforme o recomendado e foram conferidos conforme é solicitado, não há como surgir esta não conformidade. Ocorre que não há um controle de rastreabilidade dos materiais utilizados, nem um controle de datas de estocagem, não há como verificar se os locais com a não conformidade possuem materiais do mesmo lote ou o mesmo funcionário executou.

Descascamentos de pintura são as não conformidades que mais se manifestaram em esquadrias de madeira, subcategoria com maior número de ocorrências no sistema de esquadrias do empreendimento A. O descascamento de pintura não teve uma grande predominância, representando $25 \%$ das não conformidades em esquadrias de madeira, ou seja, são 10 casos para esta não conformidade de um total de 39 em esquadrias de madeira e de 66 para o sistema de esquadrias. A Figura 5 ilustra a não conformidade.

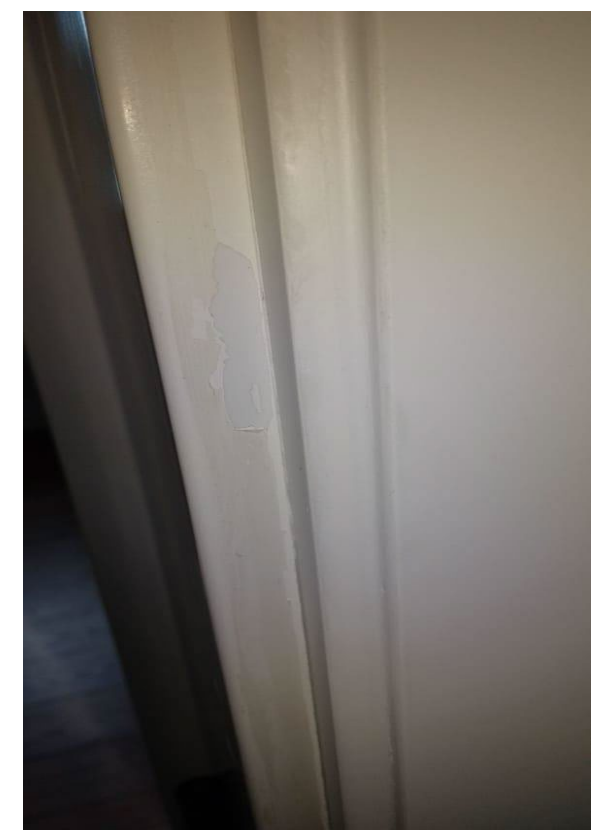

Figura 5: Descascamento de pintura em esquadrias de madeira

Para iniciar a análise, foram relacionadas todas as possíveis causas para o descascamento de tinta das esquadrias de madeira e organizadas em um diagrama de causa-efeito. Foi considerado que a causa pode estar desde a fabricação até o momento no qual foi realizada a solicitação de abertura de ocorrência junto ao setor de assistência técnica da empresa, ou seja, inclui-se a parte de transporte, estocagem, instalação e uso da esquadria. A Figura 6 ilustra o diagrama de causa-efeito gerado para este estudo.

Através de uma inspeção visual nota-se que a tinta não está aderida ao substrato onde descascou, porém, isto ocorre em partes pontuais da esquadria, sem uma localização específica. Quando o substrato foi exposto, notou-se que é liso, sem presença de rugosidade aparente, porém não pode ser colocada uma relação de causa e efeito.

Existem procedimentos por parte da construtora quanto ao recebimento e estocagem do material, além de haver para a instalação das esquadrias, que, se foram seguidos conforme o recomendado e foram conferidos conforme é solicitado, não há como surgir esta não conformidade. Ocorre que não há um controle de rastreabilidade das esquadrias, por mais que tenha identificação desde a fabricação até a estocagem, não há como verificar se todas as ocorrências são de esquadrias do 
mesmo lote. Ainda, não há uma preocupação de como a esquadria é fabricada, ou seja, tem grandes chances da causa ser uma falha durante a fabricação do item.

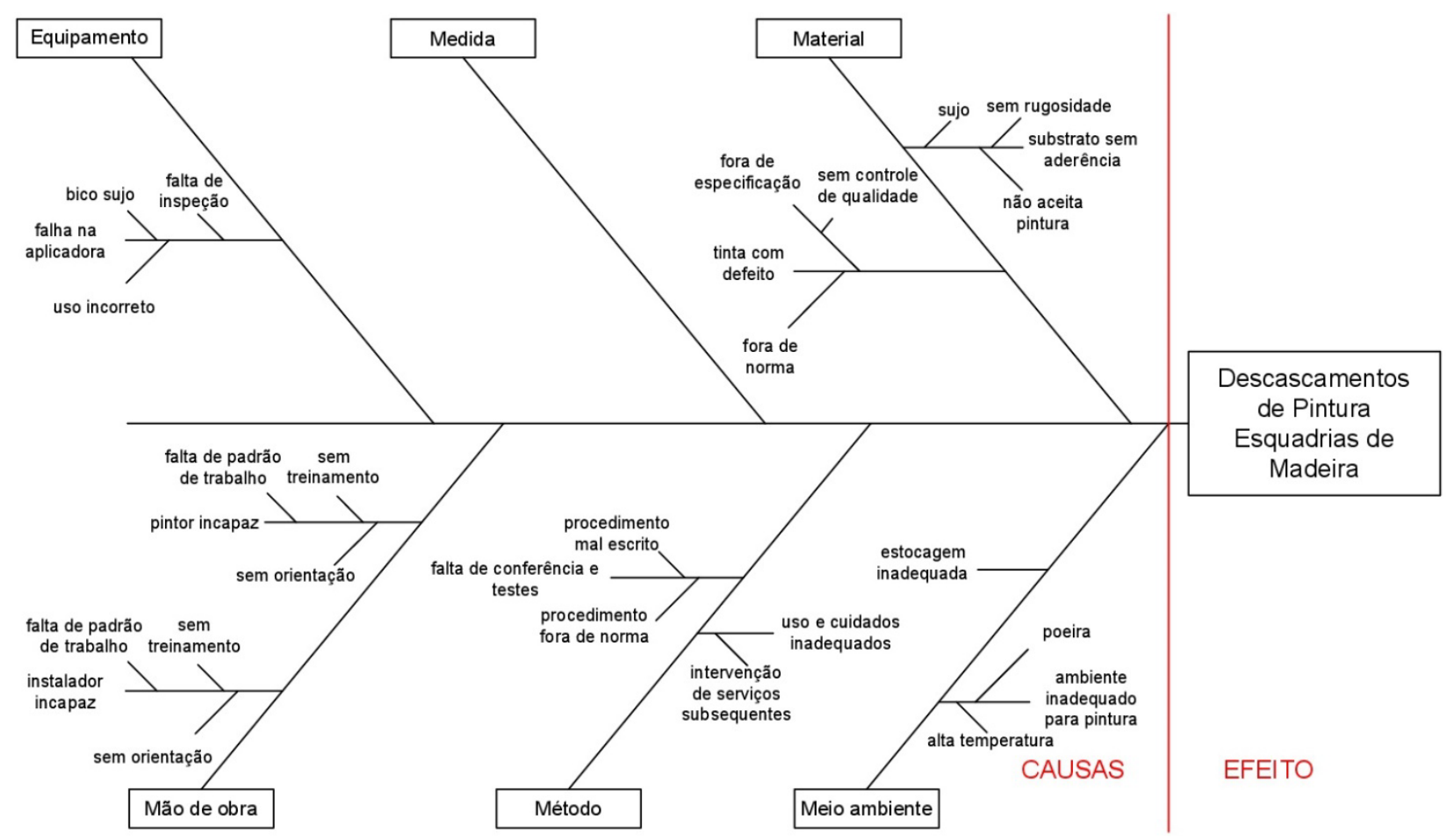

Figura 4: Diagrama de causa-efeito: descascamento de pintura em esquadrias de madeira

Não há rastreabilidade de esquadrias de madeira após a instalação, logo, a identificação dos lotes das portas durante a estocagem não teve continuidade, impossibilitando a verificar se todos os casos que houve esta não conformidade são de materiais do mesmo lote.

As fissuras são as não conformidades que mais se manifestaram em revestimentos de argamassa, subcategoria com maior número de ocorrências no sistema de revestimentos do empreendimento A. As fissuras representam $96 \%$ das não conformidades em revestimentos de argamassa, ou seja, para esta não conformidade, são 22 casos de um total de 23 em revestimento de argamassa e de 50 para o sistema de revestimentos. Todas as fissuras são de ordem estética, pois tem a característica de fissuras de retração de argamassa,

As fissuras de retração argamassa tem natureza passiva, são de pequena espessura e estão e predominantemente em ambientes internos (em ambientes externos permite a infiltração de água), mostrando que é um indício que há problema quanto à composição, execução ou ambiente de aplicação da argamassa. Pode-se verificar que a tendência de todas é baixa, ficando a classificação pendente da exposição visual ao usuário, por isso, foi selecionado o caso que ocorreu no hall de entrada do empreendimento A que está ilustrado na Figura 5. 


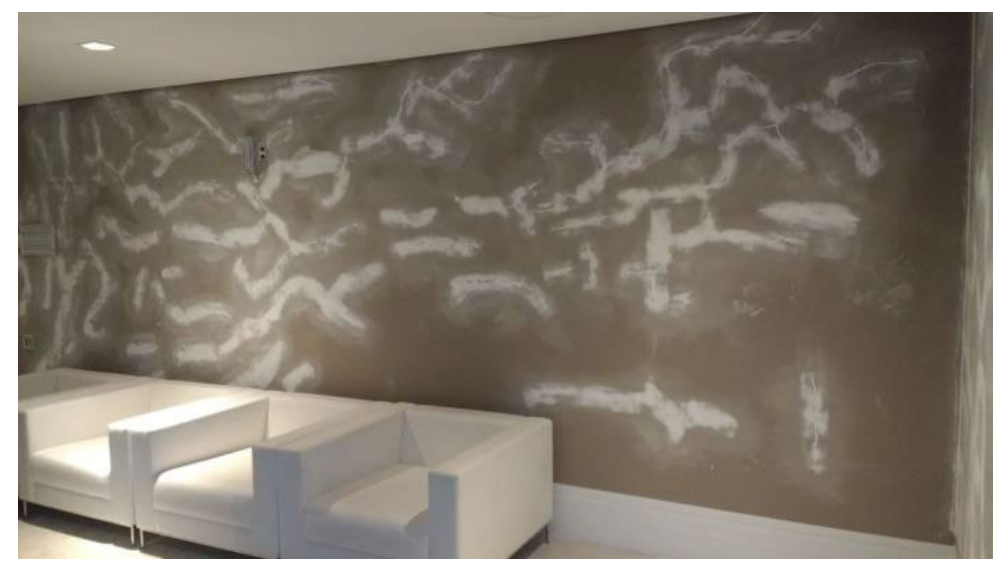

Figura 5: Caso analisado de fissuras em revestimentos de argamassa

O material utilizado para o revestimento argamassado interno deste empreendimento é a argamassa estabilizada. Como vantagens, pode-se destacar a eliminação de estoque e o manuseio das matériasprimas, diminuição do desperdício de material, eliminação do tempo de espera e a mão de obra para preparação da argamassa, além de aumentar a produtividade e a racionalização da mão de obra. Já como desvantagens, destacam-se a redução ou perda de fluidez da argamassa ao longo do tempo e maior tempo de espera para realizar o desempeno da argamassa.

A Figura 6 ilustra um caso de não conformidade semelhante a que está em estudo, apontando que são problemas de traço de argamassa utilizada.

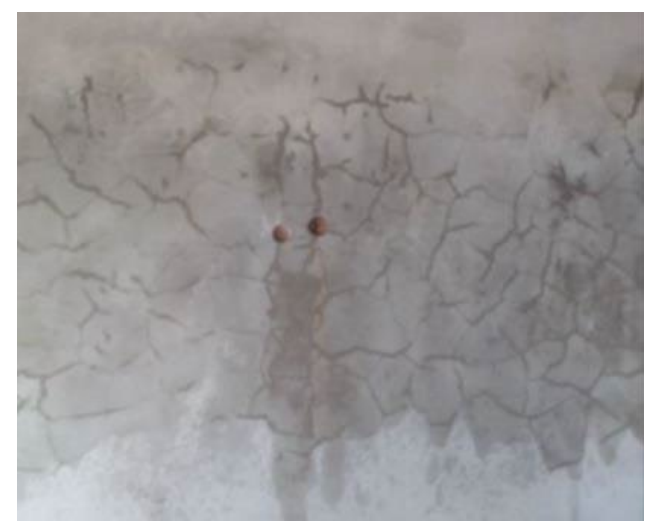

Figura 6: Caso analisado de fissuras em revestimentos de argamassa

\subsection{Empreendimento B}

As não conformidades selecionadas para serem analisadas foram as seguintes:

a) Falhas em luminárias em instalações elétricas e telefônicas;

b) Infiltrações em fachadas de vidro unitizadas.

As falhas em luminárias são as não conformidades que mais se manifestaram em instalações elétricas e telefônicas, subcategoria com maior número de ocorrências no sistema de instalações do empreendimento B. As falhas em luminárias representam $40 \%$ das não conformidades em instalações elétricas e telefónicas. Procedendo com uma analise mais detalhada, percebe-se que o grau de risco de todas é mínimo, como também a relevância, porém um caso destoa-se por se tratar da iluminação de emergência do condomínio, que é imprescindível para a segurança das pessoas que estão no empreendimento. 
No empreendimento analisado as luminárias de emergência ficam constantemente ligadas à tomada, ou seja, somente acenderão quando faltar luz, porém, foi relatado que durante uma falta de energia, elas não ligaram e que isto pode trazer problemas em caso de evacuação do condomínio, especialmente durante a noite, pois o hall de entrada faz parte de umas das rotas de saída do edifício. Para verificação deste problema, foram realizados dois testes. O primeiro consistiu em pressionar o botão de teste das luminárias de emergência do hall de entrada para verificar se estão funcionando, logo de imediato todas as luminárias acenderam. O segundo foi desligar o disjuntor que alimenta as luminárias, que também alimentam o portão de acesso de veículos do empreendimento, houve a mesma resposta que o teste anterior.

Com estes dois testes, conclui-se que luminárias de emergência não estão com vício de fabricação, uma vez que todas ligaram ao serem desligadas da tomada. Também conclui-se que há energia passando no circuito que alimenta essas luminárias, uma vez que desligando o disjuntor, as luminárias ligaram. Durante o teste do disjuntor, constatou-se que o motor do portão de garagem também parou de funcionar.

Realizando uma verificação no projeto elétrico do térreo, o portão, que foi instalado pela construtora durante a obra, estava previsto apenas como uma espera com a fiação passando, sem previsão no quadro de cargas. Esta falta de informação no projeto deve ter levado a conexão da fiação ao circuito das luminárias e, consequentemente, ligada ao gerador. Quando falta energia no empreendimento, o gerador é acionado, alimentando os circuitos que nele estão ligados, como o portão de acesso de veículos é ligado ao gerador, às luminárias de emergência também, impedindo o acionamento dessas luminárias.

As infiltrações representam $64 \%$ das não conformidades em esquadrias de aluminio, sendo as não conformidades que mais se manifestaram em esquadrias de aluminio. Uma vez que durante intempéries, as salas comerciais ou áreas condominiais tem estragos pela água que entra, o grau de risco é médio, assim como o grau de relevância. Nota-se que a maior frequência ocorreu na parte superior da esquadria, não dos montantes nem das folhas, por isso, foi selecionado um caso ocorrido numa sala comercial no $12^{\circ}$ andar, último andar antes da laje de cobertura. A Figura 7 demonstra o local que ocorreu esta não conformidade.

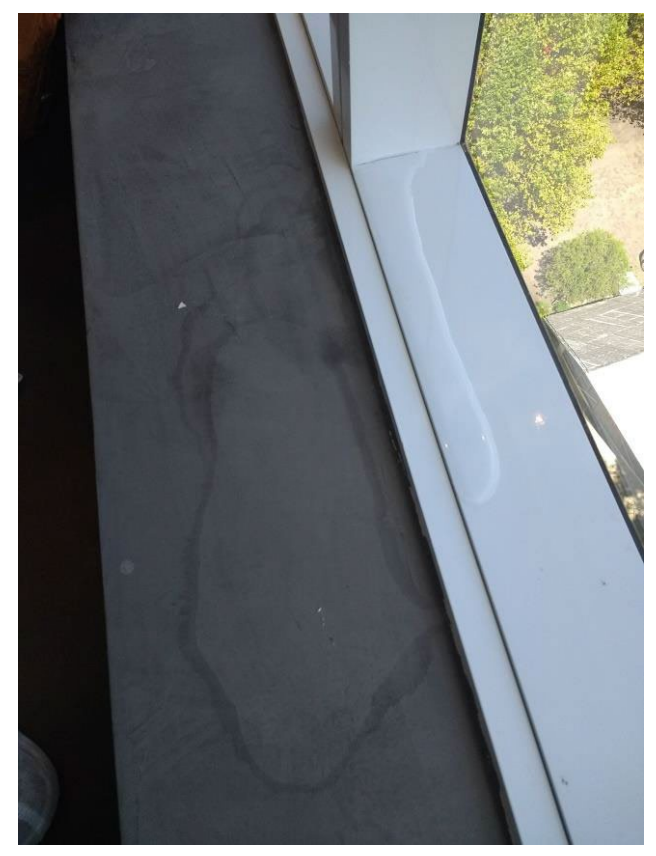

Figura 7: Mancha de infiltração da esquadria 
Quanto ao aspecto jurídico, trata-se de um vício oculto conforme o Código de Defesa do Consumidor, pois é um item que apenas surge em chuvas, sendo que os danos secundários, que são o maior indício que há esta não conformidade, podem ser dissimulados. Este tipo de não conformidade não está explícito nos prazos recomendados na NBR 15575:2013, porém pode ser adotado o prazo de três anos após o auto de conclusão do empreendimento, referente a estanqueidade de fachadas e pisos molháveis, portanto este tipo de não conformidade está em garantia pela construtora salvo modificações que podem intervir no funcionamento destas instalações.

O diagrama de causa-efeito foi montando relacionando todas as possíveis causas para a infiltração na pele de vidro. Como já mencionado, considerou-se que a causa pode estar desde a fabricação até o momento no qual foi realizada a solicitação de abertura de ocorrência junto ao setor de assistência técnica da empresa, ou seja, inclui-se a parte de transporte, estocagem e etapas de execução e utilização (Figura 8).

A fachada de vidro unitizada é composta por módulos ancorados em ganchos presentes em um suporte metálico que está fixado junto à estrutura de concreto do edifício. Os módulos da fachada do empreendimento são em vidro laminado e, em adornos e módulos que não estão visíveis do lado de dentro, por placas de ACM (alumínio composto).

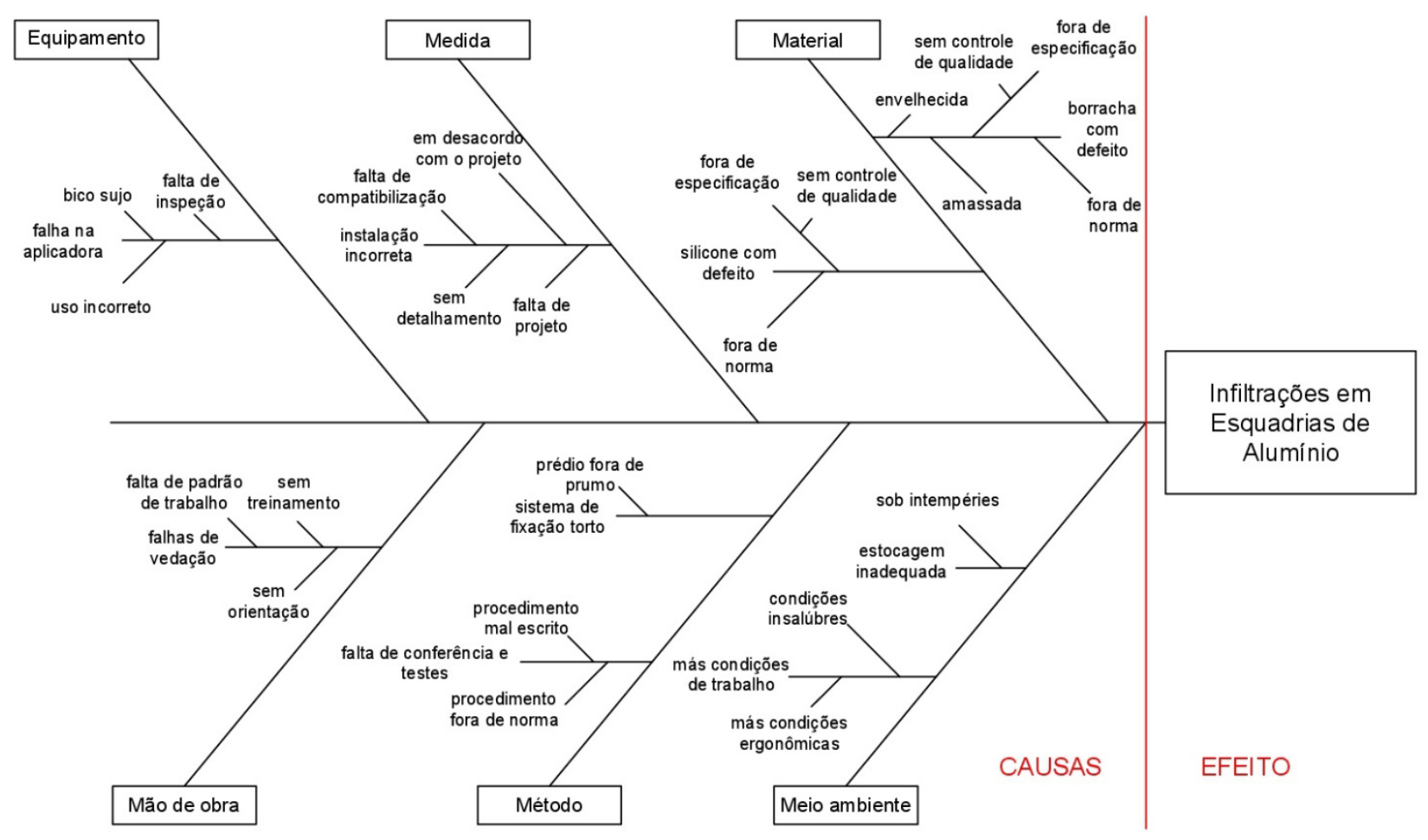

Figura 8: Diagrama de Causa-Efeito: Infiltrações em Fachadas de Vidro Unitizadas

Quando uma infiltração manifesta-se na fachada de vidro unitizada, deve-se localizar o ponto de infiltração, isso ocorre devido ao fato que este a fachada de vidro unitizada é composta por um número de células que compõem um sistema maior. Para se chegar ao ponto de infiltração da sala comercial, a empresa que foi responsável pela fachada de vidro unitizada instalou andaimes suspensos para realizar a inspeção do ponto onde está entrando água. Como está evidenciado na figura 9, trata-se de uma falha na vedação das placas de ACM. 


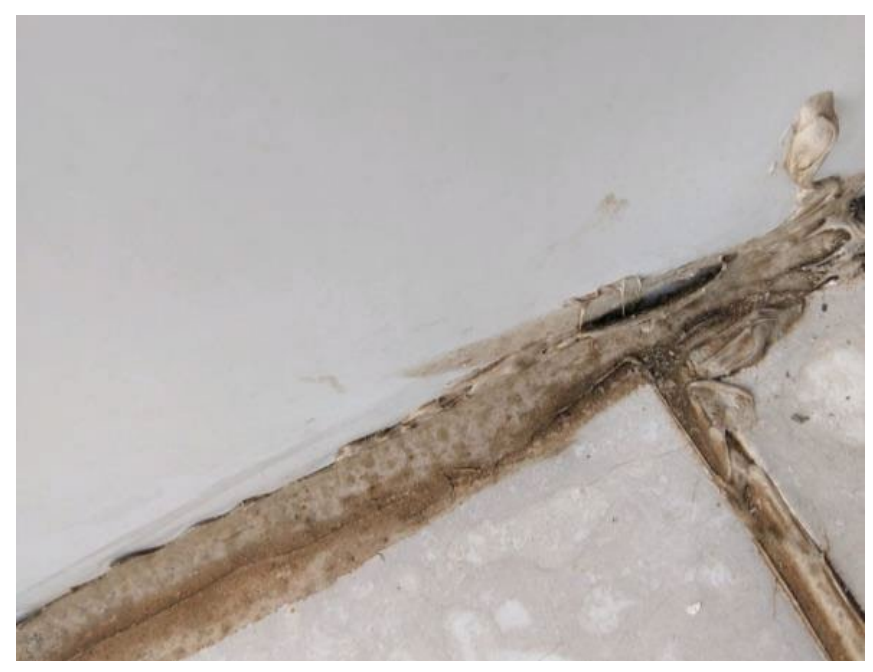

Figura 9: Falha na vedação das placas de ACM

O sistema de fachada de vidro unitizada possui um tratamento diferente na empresa. No âmbito da contratação, geralmente existe fornecedores de mão de obra e de material, porém, para fachada de vidro unitizada, é contratado um fornecedor apenas, tanto para material e mão de obra.

As placas de ACM não aceitam a aderência do silicone de vedação, portanto, a vedação deve ser realizada não somente na junta entre placas, mas fazer uma sobreposição de 3 centímetros para cada lado da junta, pois, como o silicone não está aderido, ele tende a soltar-se após períodos longos de exposição a intempéries. Este procedimento não foi realizado, não constando no procedimento de execução da fachada, ou seja, trata-se de um problema no método de realização.

\section{CONCLUSÕES}

O objetivo principal deste trabalho foi fazer um levantamento das não conformidades em dois empreendimentos com idade até dois anos e analisar as não conformidades que mais se destacam. Isto foi realizado na tentativa de encontrar padrões tanto em quais sistemas possuem maior frequência e quanto nas possíveis causas das não conformidades estudadas.

Foram analisadas um total de 471 ocorrências, sendo que 356 apresentavam alguma não conformidade. Durante o levantamento de dados e análise por diagrama de Pareto, notou-se que as mesmas três categorias possuíram as três maiores frequências para os dois empreendimentos. Apesar das categorias com maior frequência apresentarem-se as mesmas nos dois empreendimentos, as subcategorias foram diferentes para os sistemas de instalações e subsistemas de esquadrias. Isto ocorre pelo fato dos sistemas construtivos utilizados nos empreendimentos não serem exatamente os mesmos.

Ao analisar os casos selecionados para cada não conformidade, deparou-se com uma dificuldade em todos os casos: a falta de rastreabilidade, tanto de materiais como de mão de obra. Este tipo de controle facilita muito para identificar as causas relacionadas a mão de obra, equipamento e material, pois abre um horizonte para estudar todos os fatores que resultam na atividade de execução do serviço.

A garantia da qualidade é primordial para alcançar a total satisfação do cliente, e para isto ocorrer, todos os processos e colaboradores devem estar alinhados. Este artigo evidencia a necessidade de existir um controle da qualidade em todos os niveis da obra, de forma a atingir uma melhor satisfação do usuário. 


\section{REFERENCIAS}

Adami, L. H. P. (2008), Análise das Não-Conformidades em Edifícios no Período de Assistência Técnica. Monografia em Engenharia Civil (Universidade Católica do Salvador), 2008.

Associação Brasileira de Normas Técnicas. (2013). NBR15575: Edificações habitacionais desempenho - parte 1: requisitos gerais.

Brocka, B., Brocka, M. S. (1994), “Gerenciamento de qualidade”. Makron Books, São Paulo, Brasil.

CBIC (2021), ABNT cria Comissão de Estudo de Garantias das Edificações. Disponivel em: https:/cbic.org.br/inovacao/2021/03/10/abnt-cria-comissao-de-estudo-de-garantias-das-

edificacoes/.

Carvalho, M. M. (2005), “Histórico da Gestão da Qualidade” in: Carvalho, M. M., Paladini, E. P. (Org.). Gestão da qualidade: teoria e casos. Elsevier, Rio de Janeiro, Brasil, 2005. p. 01-24.

Covelo Silva, M. A., Frolini, C. B. (2019), "Manual de Desempenho do Sistema de Alvenaria de Blocos Cerâmicos City”. Ceramica City, Cesário Lange, So Paulo, Brasil.

Del Mar, C. P. (2015), Direito na construção civil. PINI, São Paulo, Brasil.

Instituto Brasileiro de Avaliações e Perícias de Engenharia. (2012). Norma de Inspeção Predial Nacional.

Miguel, P. A. C. (2005), “Gestão da Qualidade: TQM e Modelos de excelência” in: Carvalho, M. M., Paladini, E. P. (Org.). Gestão da qualidade: teoria e casos. Elsevier, Rio de Janeiro, Brasil, 2005. p. 85-124.

Moreira, L. C. (2019), Vida útil e prazos de garantia sob a ótica da norma de desempenho - NBR 15.575. Disponivel em: https:/www.creago.org.br/noticia/view/171/vida-util-e-prazos-degarantia-sob-a-otica-da-norma-de-desempenho-nbr-15575.

Souza, R. et al. (1995), Sistema de gestão da qualidade para empresas construtoras. Editora PINI, São Paulo, Brasil.

Thomaz, E. (2001), Tecnologia gerenciamento e qualidade na construção. Editora PINI, São Paulo, Brasil. 